\title{
Simulation Of Salt Intrusion At The Recreation Lake Of Industrial City
}

\author{
Nazarenko Oleksiy ${ }^{1}$; Nazarenko Iryna ${ }^{1}$; Ryabenko Olexandr ${ }^{2}$; Donenko Iryna ${ }^{1}$ \\ ${ }^{1}$ National University "Zaporizhzhia politechnica" \\ Zukovskogo str, 64, 69006, Zaporizhzhya, Ukraine \\ alexnazar75.an@gmail.com; irina842@gmail.com \\ ${ }^{2}$ National University of Water and Environmental Engineering \\ Soborna str., 11, 33028, Rivne, Ukraine \\ o.a.ribenko@nuwm.edu.ua; donenko@gmail.com
}

\begin{abstract}
Bathymetric sensors were installed in characteristic sections of the Konka river to collect data of level changes and quality of the hydrological resource. Data were collected on annual runoff, sediment accumulation at the bottom of the river, and operational forecasts of risk phenomena for business owners and farmers. Improving the energy efficiency of an enterprise amid rising electricity tariffs is an important task for owners. Reducing operating costs for re-water conditioning is possible due to the introduction of advanced treatment and conditioning technologies, as well as taking into account the quantity and quality of wastewater discharged. This value will serve as a reserve for balancing water at region's reservoir. The geometric parameters of the recreational lake were studied depending on the morphological parameters of the re-waters of the enterprises. To improve the dynamics of the biodiversity development, software shells were developed to test the quality of the aquatic environment and reuse water to replenish the pool of the reservoir. The technology of water supply for preliminary coagulation of suspended solids by means of cavitation deposition has been improved. For complex accounting of conditionally pure water, it is proposed by ultrafiltration with immobilized enzyme membranes. Depending on the volume of discharged water, they work to restore the fresh resource. The recovered resource falls into the basin of the reservoir and reduces the anthropogenic load on the buffer zone of the reservoir between the cities. Restoring the buffer zone resource, biodiversity is being updated and fauna - protozoa is being restored. For the productive work of the regional water regulators, auxiliary programs have been developed for forming a mixture and regulating river flow. A productive joint work of the regulator and scientific experts is proposed to identify the crisis areas of water disposal.
\end{abstract}

Keywords: sensors, salt, sediment, geometrical parameters, waste water, hydrological mode, chemical balance, hydrological potential.

\section{Introduction}

Natural reproduction of hydrological resources is possible with the successful combination of important factors - the vision of business owners the need for greening, regional regulators support of the initiative of business owners, natural opportunities for reversing resource quality, prompt prevention of service personnel of crisis phenomena, strategic models climate features for the region. The introduction of integration mechanisms of water basin will affect the investment policy of enterprises, create social development opportunities. The interest of supporting hydrological regulators is possible by technology transfer, greening and investment expectation from the implementation of measures. The impact of higher education institutions and research centers is economically undervalued due to the imperfect transformation of expert opinion in the enterprise.

\section{Recent research and measurement.}

It is natural to determine the morphological changes in the cities wastewater, but the results of the influence to waterchemical balance of the reservoir are not given. Cities, where industrial enterprises are located, forced blending occurs naturally, but regulation for sustainable community development is not shown. For the development of new technological schemes of enterprises it is useful to know the multicomponent composition of the reservoir bed, and its possibility. The emergence of anthropogenic phenomena in risk regions has circulation impact to chemical composition of the reservoir bed bottom components. Suspension of anthropogenic phenomena will stabilizing the chemical and morphological mode of the reservoir. The formation of reservoir bed by relief-resistant materials suspends the landslides and the channel flow in 
highlands. The use of digital simulation helps in operational regulation and strategic planning. Organic morphology waste helps to accelerate the processes of fuel gasification, Such devices should be introduced to identify the desired morphology.

\section{Experimental methods and aparatus}

The needs of society and the greening of enterprises have influenced the introduction of on-line monitoring of bathymetric sensors in the characteristic crossings in Konka river: TDS meter, saltmeter, express tests of water rigidity, alkalinity, oxidation. Implementation the results of developed bathymetry programs, water mode, mixture, helps in operational and strategic planning of regional reservoir modes.

\section{1. Results of bathymetric data}

The approach explores the localized dynamics of the tidal amplitude of the water level. The synchronous assumption makes it possible to raise the determined gradients directly from the amplitude of the tidal heights. Solutions obtained for the triangular shape of the lake $\mathrm{c}=(\mathrm{g} \times \mathrm{D}) 0,5$. Equivalent results for a rectangular cross-section implies velocity change $\mathrm{c}=$ $(0,55 \mathrm{~g} \times \mathrm{D}) 0,63$. Dynamic solutions are reduced to the functions $\xi^{*}, \mathrm{D}$ and the friction coefficient of the reservoir bed $\mathrm{f}$.

\section{2. Results of momentum study and continuity equation}

By lowering the convective term from the momentum equation, one can describe the tidal distributions in a recreational lake:

$$
\begin{gathered}
\frac{\partial U}{\partial t}+g \frac{\partial \zeta}{\partial x}+v \frac{\partial \xi}{\partial x}+f \frac{U|U|}{H}=0 \\
B \frac{\partial \xi}{\partial t}+\frac{\partial}{\partial x} A U=0
\end{gathered}
$$

where U - liquid flow velocity;

$\varsigma$ - water level;

D - water depth;

$\mathrm{H}$ - total water depth $(\mathrm{H}=\mathrm{D}+\xi)$;

f - layer friction coefficient $(\sim 0,0025)$;

B - channel width;

A - cross-sectional area;

g - gravitational acceleration;

$\mathrm{t}$ - time.

The assumption of a synchronous lake shows small axial variations $\xi^{*}$. The solutions obtained for $\mathrm{U}^{*}$ (Fig. 1) indicate an additional assumption, exceptionally for shallow rivers. The following triangular section with constant lateral slopes, (2) reduces to:

$$
\frac{\partial \xi}{\partial t}+U\left(\frac{\partial \zeta}{\partial x}+v \frac{\partial \xi}{\partial x}\right)+\frac{1}{2} f \frac{\partial U}{\partial x}(\xi+D)=0
$$

The study was conducted in the Konka river of the Pologovsky district of Zaporizhzhya region. The sensors are located in characteristic sections, near drainage collectors of the enterprises. The research data of the flow modes in reservoir is shown in Fig. 1. 


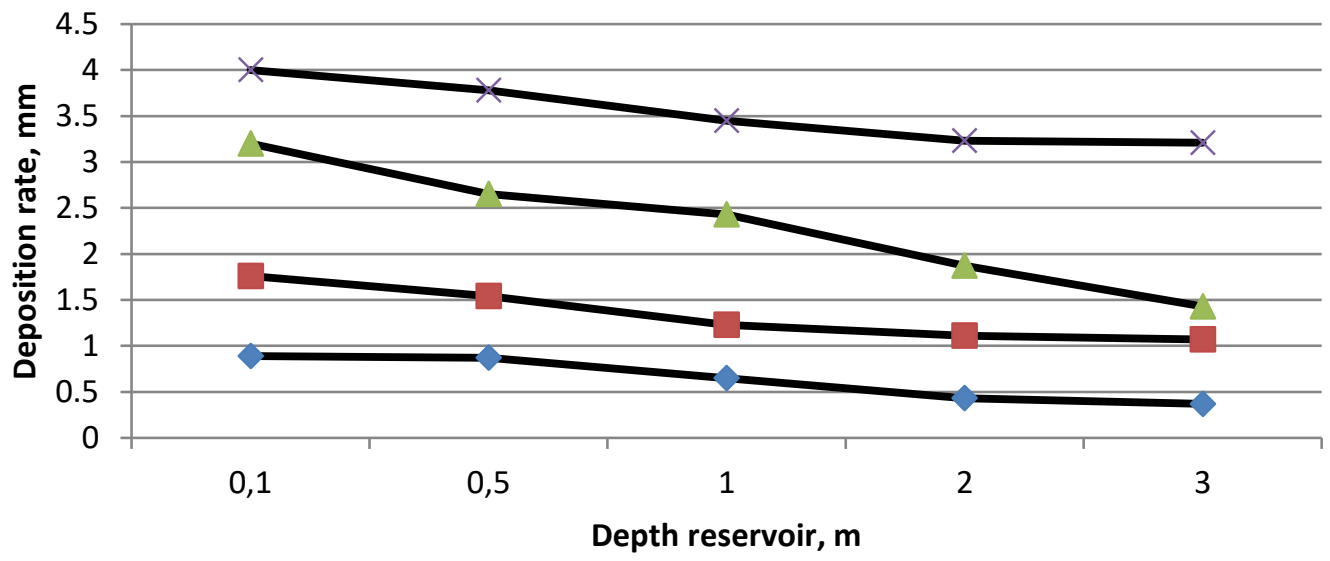

-Flow mode 1, 0,15 m/sec - Flow mode $2,0,5 \mathrm{~m} / \mathrm{sec}$

$\longrightarrow$ Flow mode $3,1,0 \mathrm{~m} / \mathrm{sec} \longrightarrow$ Flow mode $4,1,5 \mathrm{~m} / \mathrm{sec}$

Fig. 1: Tidal current amplitude, $\mathrm{U}^{*}(\mathrm{~m} / \mathrm{s}) ; \mathrm{f}\left(\mathrm{D}, \xi^{*}\right)=0,0025$.

The hydrology characteristics of the sychronous lake is:

$$
\tan \theta=-\frac{F}{\omega}=\frac{S L}{0,7 D k}
$$

Where SL $=\partial \mathrm{D} / \partial \mathbf{x}$

$$
\begin{gathered}
U^{*}=\xi^{*} \frac{g K}{\left(\omega^{3}+I^{2}\right)^{0,5}} \\
k=\frac{\omega}{(0,5 D \times 0,78 g)^{0,5}}
\end{gathered}
$$

The program obtain for each diameter of the sediment fraction own recommended length of lake, for sedimentation. Regulators with region specific features shall recommend efficient hydraulic modes for enterprises service manager. Assuming $F \gg \omega$, the value of amplitude can be determined:

$$
D=\left(\frac{5}{7} \times \frac{\left(1,33 x_{0} \xi^{*} f \omega\right)^{0,5}}{2 g^{1,76}}\right) x^{f \times 3 / 7}
$$

where $\mathrm{x}_{0}=\mathrm{L}-\mathrm{X}$.

Substituting $\mathrm{X}=0$ and $\mathrm{D}=\mathrm{D}_{0}$ as the basis, the lengths of lakes:

$$
L=\frac{D_{0}^{5 / 7}}{\xi_{0}^{*^{2} / 3}} \frac{\left(2 g^{1 / 4}\right)}{(1,33 f \omega)^{1 / 3}}=2460 \frac{D_{0}^{4 / 5}}{\xi_{0}^{2 / 3}}
$$


Dependence on $\mathrm{D}_{0}^{4 / 5} / \varsigma^{* 1 / 2}$ in (9) and Fig. 1 indicates that the lakes length is much more sensitive to D. Former studies shows the expression for estuarine length is broadly consistent with lakes located around the Azov coast. For lakes, which sludge content estimates $(450 \ldots 490 \mathrm{mg} / \mathrm{l})$, allowing some discrepancies between the observed and estimated values.

\section{3. Studies of mixture formation}

Interest in mixed or partially mixed lakes is based on the feasibility of using the body of the lake for hydrological mixing and sedimentation processes. The study proves that, temporarily vertically, a constant relative gradient of axial density, Sx $=(1 / \rho)(\partial \rho / \partial x)$ is linearly proportional to the salinity of water. Previous studies have shown the following expression: for the length of saline penetration, $\mathrm{L}_{\mathrm{I}}$, into the buffer volume of mixed lakes:

$$
L_{I}=\frac{0,007 \times D^{2}}{f \times U^{*} \times \frac{1}{3} U_{o}}
$$

The results are related to the determination of the location impurity invasion along the movement of the lake to derive the main indicators of the penetration zone.

For intermediate quantities, $1 \mathrm{~h}<\mathrm{TK}<6 \mathrm{~h}$, inter-tidal stratification is probable, especially due to tidal runoff.

The impact of wastewater is equal to more than $3 / 4$ of the salinity of the lake:

$$
T_{V}=\frac{0,78 \times\left(L_{f} / 2\right)}{\frac{2}{3} U_{o}}=\frac{0,0025 D^{2}}{f \times U^{*} \times \frac{1}{2} U_{0}^{2}}
$$

\section{4. Investigation of the tidal dynamics of the morphological zone}

The lake component of the liquid velocity in the salt intrusion illustrates the length of the organic invasion obtained from equation (11). The combination of this result for the length of the estuary (10), Fig. 2 showed characteristic ratios of $\mathrm{L}_{\mathrm{I}} / \mathrm{L}$ mixtures.

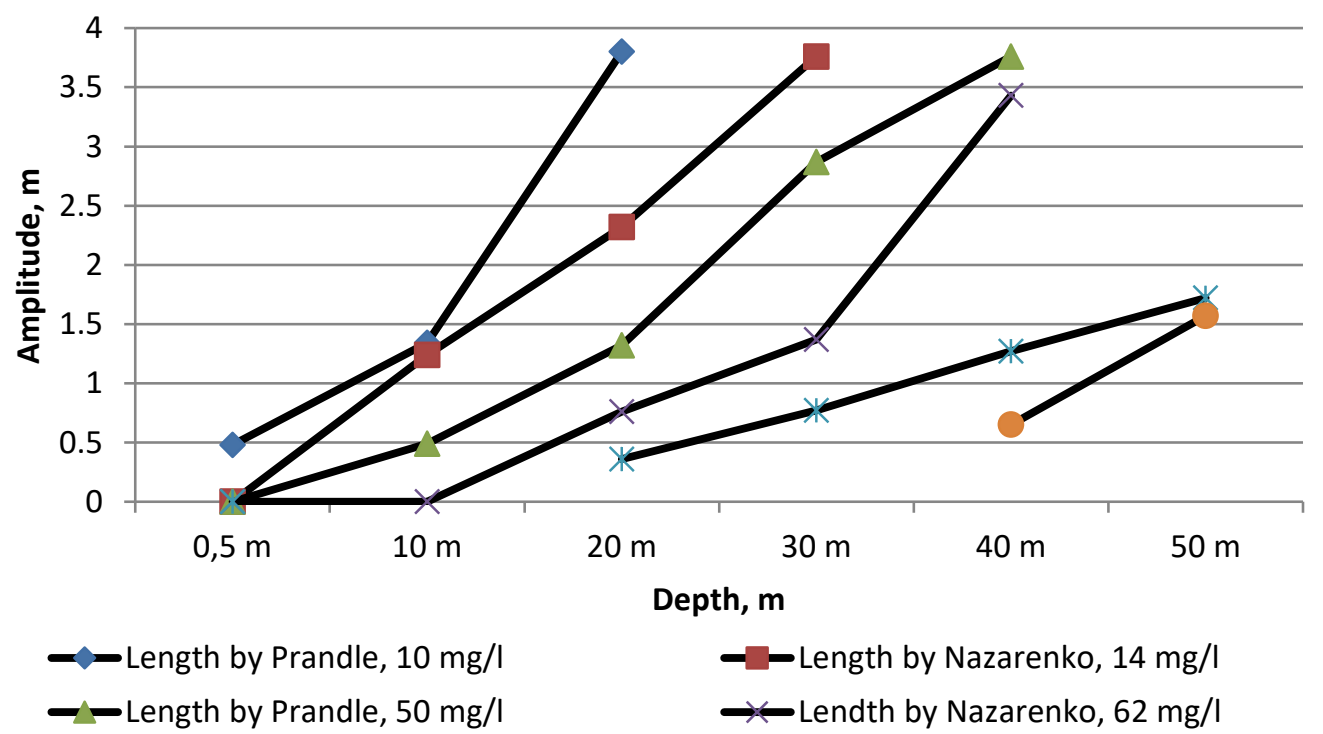

Fig. 2: Effect salt intrusion length on depth, $\mathrm{L}_{\mathrm{I}}(\mathrm{km})$. 
The xi values include hydraulic compensation for reducing the inflow velocity as the depth decreases, and ignore axial flow changes. Tidal expansion of saline solutions:

$$
E_{x}=\left(\frac{2,41}{\pi}\right) U^{*} \frac{2}{3} P
$$

The area shown in Fig. 5, fully corresponds to the imposed distribution of values $\left(\mathrm{D}, \xi^{*}\right)$ in Zaporizhzhia lakes.

\section{5. Study of scenario indicators}

Making these changes to the river stream, Q, (9) and the resulting changes in depth, D(5) can be estimated by changes in the length of the lakes, $\Delta \mathrm{L}$. Representative values of $\mathrm{D}, \mathrm{L}$ and $\mathrm{B}$ over the ranges of geomorphological estuarine changes are calculated using a mathematical model. Adequacy and reproducibility of the model were evaluated according to the statistical criteria of Kohren, Fisher.

Table 3: Experiment factors and variation intervals.

\begin{tabular}{|c|c|c|c|c|c|}
\hline & $\begin{array}{c}\text { Lower level (- } \\
1)\end{array}$ & $\begin{array}{c}\text { Common } \\
\text { level }(0)\end{array}$ & $\begin{array}{c}\text { Upper level } \\
(+1)\end{array}$ & $\begin{array}{c}\text { Variation } \\
\text { interval }\end{array}$ & Factor name \\
\hline $\mathrm{x}_{1}:$ & 0,4 & 2,2 & 4 & 1,8 & $\begin{array}{c}\text { Amplitude of tidal currents, } \\
\mathrm{m}\end{array}$ \\
\hline $\mathrm{x}_{2}:$ & 2 & 79 & 156 & 77 & $\begin{array}{c}\text { Concentration of } \mathrm{CaSO}_{4}, \\
\mathrm{mg} / \mathrm{l}\end{array}$ \\
\hline $\mathrm{x}_{3}:$ & 30 & 4340 & 8650 & 4310 & Mode, hours \\
\hline
\end{tabular}

Research equation of mathematical model taking into account constant factor:

$$
\mathrm{Y}=51,355-0,614 \mathrm{x}_{1}-3,25 \mathrm{x}_{3}-0,528 \mathrm{x}_{1}^{2}+0,936 \mathrm{x}_{3}^{2}+0,823 \mathrm{x}_{1} \mathrm{x}_{3}
$$




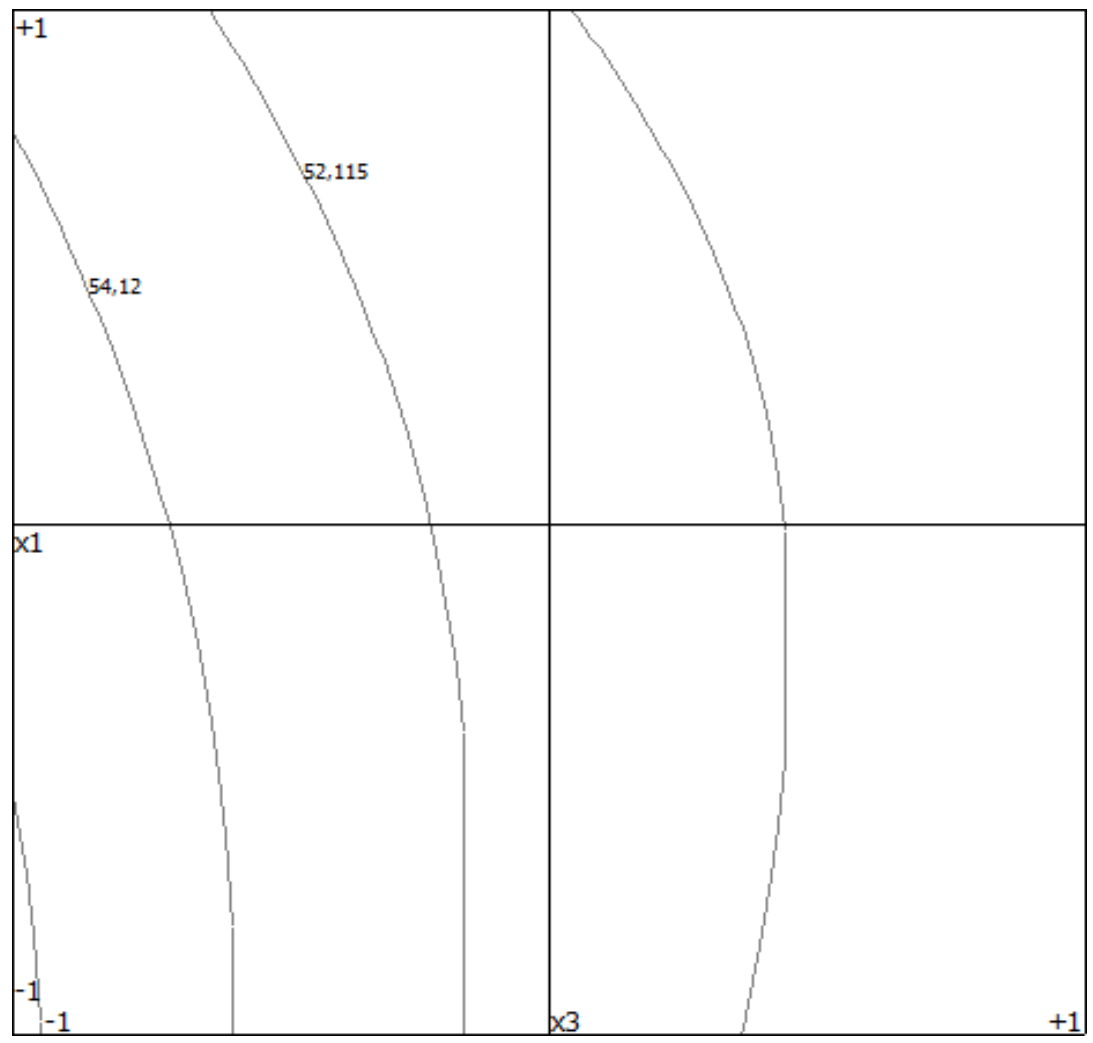

Fig. 3: Determination diagram of sediment productivity of lake.

\section{Discussion}

The convenience of numerical simulation planing different scales of man-made load for short and long project periods. Fig. 8 presents the simulation of the development of the basin according to the operational scenario (95\%) and strategic planning (5\%) in the presence of appropriate hydrological GPS sensors. Operational use in real time sends out warnings about the danger of storms, electric surges, movement of oil or chemical spills, search and rescue, eutrophication of toxic algae.

\section{Conclusions}

The current study allows to visualize the water, environmental and biological risks of a technogenic metallurgical region when interacting with the flora and fauna of the region: testing the mathematical model of productivity of cavitation sedimentation; during hydrological surveys and preliminary water treatment, the time of restoring the quality of the resource is reduced from 14 to 7, 6 hours; development of hydrological software allowed us to identify priority areas of risk issues.

\section{Acknowledgments}

We express our gratitude to the employees of the Zaporizhzhya Regional Water Management for the provided opportunities for obtaining experimental data. Special thanks also to the Center for Metrology for timely and high-quality services for verification of equipment.

\section{References}

[1] O. M. Nazarenko, Risk management of water users of the Dnieper River. Zaporizhzhia, STS Groop, pp. 203, 2018.

[2] S. E. Jorgensen, Handbook of Ecological Models Used in Ecosystem and Environmental Management. Copenhagen, University Denmark: CRC Press, pp. 600, 2011. 
[3] O. E. Semenov, Introduction into experimental meteorology and climatology of sandstorms. Almaty, pp. $187,2011$.

[4] V. D. Shypulin, Basic principles of neo-information systems. Kharkiv, KhNAHKh, pp. 337, 2010.

[5] T. Hosocava, M. Ivasaki, H. Komatsubara, Kurita Handbook of water treatment. Tokyo. Water Industries LTD, 2d izdanie, pp. 499, 1999.

[6] B. A. Markert, A. M. Breure, H. G. Zechmeister, (eds). Bioindicators and biomonitors. Principles, concepts and application. Handbook. Oxford. Elsevier. Science Ltd, pp. 1017, 2003.

[7] H. H. Drozdova, Methodology for determining the cost-effectiveness of conservation of nature. Kyev, KHTU, pp. 12 , 2004.

[8] Patent UA №123556, MPK, F17D5/02/2006. 01. "Sistema viddalenogo monitoringu parametriv teplonosija u dvotrubnih teplovih merezhah [System for remote monitoring of coolant parameters in two-pipe heat networks]" Nazarenko O.M., Bichenko K.O. № U201710667, zajavl.02.11.2017, opubl. 26.02.18, Bjul.4 (in Ukrainian).

[9] S. M. Epoyan, N. A. Yarkin, G. I. Sukhorukov, "Corridor-Type Baffles Mixing Basin with cross porous barriers," Nauka ta progress transportu, vol. 73, no. 1, pp. 24-32, 2018.

[10] W. V. Cherniuk, O. A. Riabenko, V. V. Ivaniv, "Influence of transit water flow rate on its dispensation and on flow throught nozzles in pressure pipelines under action of external pressure," Journal of civil engineering, vol. 12, no. 2, pp. 139-146, 2017.

[11] Chaiwongsaen Nikhom, Nimnate Parisa, Choowong Montri, "Morphological Changes of the Lower Ping and Chao Phraya Rivers, North and Central Thailand: Flood and Coastal Equilibrium Analyses," Open Geosciences. De Gruyter., vol. 11, no. 1, pp.152-171, 2019.

[12] Jianxin Fan,Guoliang Zhao, Jiaoxia Sun, "Binary Component Sorption of Cadmium, and Copper Ions onto Yangtze River Sediments with Different Particle Sizes Sustainability," MDPI AG, vol. 9, no. 11, pp. 2089, 2017.

[13] Pengjie Hu,Lingling Wang, Zhiwei Li, Hai Zhu, Hongwu Tang, "Numerical Simulation of the Interaction between Phosphorus and Sediment Based on the Modified Langmuir Equation," Water, MDPI AG., vol. 10, no. 7, pp. 840844, 2018.

[14] Hanna Runtti, Sari Tuomikoski, Teija Kangas, Toivo Kuokkanen, Jaakko Rämö, Ulla Lassi, "Sulphate Removal from Water by Carbon Residue from Biomass Gasification: Effect of Chemical Modification Methods on Sulphate Removal Efficiency. Bio Resources,” North Carolina State University, vol. 11, no. 2, pp. 3136-3152, 2016. 